\title{
Research Paper: Effects of Eight Weeks of Resistance Exercises on Neurotrophins and Trk Receptors in Alzheimer Model Male Wistar Rats
}

\author{
Gholamhasan Jafarzadeh $^{1}$ (D), Saeid Shakerian ${ }^{* *}$ (i), Yaghoob Farbood $^{2}$ (i), Mohsen Ghanbarzadeh ${ }^{1}$ (i)
}

1. Department of Sport Physiology, Faculty of Sports Sciences, Shahid Chamran University of Ahvaz, Ahvaz, Iran

2. Department of Physiology, Khalij Fars Physiology Research Center, School of Medicine, Ahvaz Jundishapur University of Medical Sciences, Ahvaz, Iran

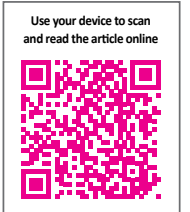

cittention: Jafarzadeh, Gh., Shakerian, S., Farbood, Y., \& Ghanbarzadeh, M. (2021). Effects of Eight Weeks of Resistance Exercises on Neurotrophins and Trk Receptors in Alzheimer Model Male Wistar Rats. Basic and Clinical Neuroscience, 12(3), 349-360. http://dx.doi.org/10.32598/bcn.2021.2067.1

http://dx.doi.org/10.32598/ben.2021.2067.1

Article info:

Received: 22 Sep 2019

First Revision: 25 Oct 2019

Accepted: 01 Mar 2020

Available Online: 01 May 2021

Keywords:

Resistance exercises,

Neurotrophins, Trk receptors,

Alzheimer, Rat

\section{A B S T RA C T}

Introduction: This study evaluates the effects of 8 weeks of resistance exercises on the expression of neurotrophins and Trk receptors in Alzheimer model male Wistar rats.

Methods: For this purpose, 32 mature male Wistar rats with a mean weight of 230-280 g were chosen and divided into Alzheimer and Sham groups. The rats in the sham group received normal saline, while the ones in the Alzheimer group received streptomycin via intraventricular injection. These rats were then divided into the following four subgroups: 1) resting sham, 2) exercising sham, 3) resting Alzheimer, and 4) exercising Alzheimer. The two exercising rat subgroups exercised three times a week for 8 weeks. A weight was attached to their tails, and they had to carry it on a 26-step ladder in each cycle. Resting groups were handled every day to minimize the effects of stress. At the end of the eighth week and 24 hours after the last exercise session (to avoid the effects of the last exercise session), the rats were put under deep anesthesia and beheaded. Hippocampus tissues were precisely extracted, and samples were sent to the laboratory for molecular and cellular tests. To investigate gene expression, quantitative RTPCR was used.

Results: The tests for comparing the mean values of BDNF, NT3, NGF, TrkA, and TrkB in two rat groups showed that with error levels of less than $5 \%$, there is a significant difference in the amounts of BDNF, NT3, NGF, TrkA, and TrkB between exercising rats and resting ones. These amounts were much higher in the exercising Alzheimer rats group.

Conclusion: Eight weeks of resistance exercises increased the expression of $B D N F, N T 3$, and $N G F$ genes and TrkA and TrkB receptors in Alzheimer model Wistar rats. 


\section{Highlights}

- The 8 weeks of resistance exercises increased the expression of BDNF, NT3, and NGF genes and TrkA and TrkB receptors in the Alzheimer model Wistar rats.

- The resistance exercises can be used as a proper model to help patients with AD.

\section{Plain Language Summary}

Several diseases cause progressive damage to higher functions, one of which is Alzheimer's Disease (AD), a neurodegenerative disorder. As the most prevalent chronic disease of the elderly, Alzheimer's Disease causes irreversible neuron damage. AD's symptoms comprise losing memory and other intellectual activities. In this study, experiments were performed on male Wistar rats weighing 230-280 g prepared from the animal reproduction center of Ahvaz Jundishapur University of Medical Sciences, Ahvaz City, Iran. The rats were kept in a room with a $22 \pm 2^{\circ} \mathrm{C}$ temperature under 12 hours dark/12 hours light cycle with access to food and water ad libitum. The rats were divided into sham and STZ (Streptozotocin) groups, receiving normal saline and streptozotocin via Intracerebroventricular (ICV) injection in cerebral ventricles. This study showed that the learning and memory of the rats that received STZ via ICV injection were significantly lower than those in the sham group. Moreover, resistance exercisers improved learning in Alzheimer rats. In addition, resistance exercises increased the expression of the BDNF gene, other neurotrophins, and Trk receptors.

\section{Introduction}

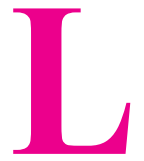

earning and memory are essential abilities for the survival of human beings. Several diseases cause progressive damage to higher functions, one of which is Alzheimer Disease (AD), a neurodegenerative disorder. As the most prevalent chronic disease of the elderly, $\mathrm{AD}$ causes irreversible neuron damage. AD's symptoms comprise losing memory and other intellectual activities. $\mathrm{AD}$ is known as the most common form of dementia (Meamar et al., 2013). This disease is a proteinopathy characterized by the production of abnormal proteins (Mayeux, 2003). The main pathological hallmarks in $\mathrm{AD}$ are the presence of extracellular amyloid plaques, primarily consisting of Amyloid- $\beta$ (A- $\beta$ ) peptide, and the accumulation of paired helical filaments of hyperphosphorylated tau protein (PHF-Tau) within neurons (Furcila, DeFelipe \& Alonso-Nanclares, 2018).

$\mathrm{AD}$ is associated with advanced dementia that is neuropathologically characterized by losing many brain neurons, especially in the hippocampus area. It is also associated with deposition of Amyloid- $\beta$ (A- $\beta$ ) protein in vascular walls, the extension of neurotic plaques, and formation of intercellular neurofibrillary tangles (Mohaddes Aredebili et al., 2011). These disorders specifically involve cortex areas, hippocampus, middle and temporal lobes. In addition, this disease is associated with abnormal function of mitochondria, oxidative damage to neu- rons, destruction of synapses, neuron degeneration and, cognitive and perceptional disorders (Jellinger, 2009). Patients with cognitive dysfunction show a decrease in their blood flow. This decrease is associated with the intensity of cognitive impairment, and neuropsychological tests confirmed it. Likewise, AD patients' cerebral blood flow is low. This index is so sensitive that it can differentiate between healthy subjects and those with mild cognitive impairment. In other words, a quantitative measurement of total brain blood flow could show vascular dysfunction and low brain perfusion in the early stages of AD (de Eulate et al., 2017). A decrease in neurons in regions related to learning and memory, especially in the hippocampus, is one of the symptoms observed in $\mathrm{AD}$ (Mohammadzadeh, Alipour \& Khallaghi, 2014).

Hippocampus is one of the two neurogenic areas in the brain that are highly affected by exercise. Brain-Derived Nneurotrophic Factor (BDNF) distribution has been reported in different parts of the brain and with a high level in the hippocampus, which is the main region for the formation of memory and learning (Yuan \& Yankner, 2000). Evidence shows that alteration of BDNF signaling is crucial for the effectiveness of exercise on hippocampus plasticity. This fact can adjust the plasticity, and synaptic transmission since blocking this signaling pathway inhibits exercise-induced memory and learning (Vaynman, Ying \& Gomez-Pinilla, 2004). Recently, it has been found that regular physical activity as an integral part of a healthy lifestyle affects compatibility ad- 
justments and especially the hippocampus, which plays a crucial role in learning and memory.

A wealth of evidence suggests that physical activity positively affects both cognitive function and cellular pathologies of AD. Aerobic Exercise (AE) stimulates the function of antioxidant enzymes and the synthesis of neurotrophic factors. It suppresses the level of the neuroinflammatory marker and boosts learning and memory. It also improves cell survival and upregulates A- $\beta$ clearance. AE reduces the levels of soluble A- $\beta 1-42$ via an increase in enzyme activity. This procedure accounts for the upregulation of $A-\beta$ clearance in the brain. It also represses apoptotic cascades such as the caspase-3, -9, cytochrome $\mathrm{C}$, and Bax. Although no clear data supports the effects of Resistance Exercise (RE) on $\mathrm{AD}$, few articles have studied the effects of RE on models of aging. In these studies, RE increased the serum concentrations of Insulin-like Growth Factor-1 (IGF-1) and BDNF, reduced oxidative stress in humans, and upregulated the hippocampal expression of BDNF mRNA in animals. Besides, RE and AE therapies may help do daily activities and enhance physical ability in AD patients. Eventually, exercise therapy regimens may assist treatment options and slow AD progression without side effects (Özbeyli \& Kasımay Çakır, 2017).

Despite many research studies performed on neurotrophins and assessing the mechanism of the effect of exercising on their function, there is still much ambiguity in this subject. The related studies have been mostly focused on BDNF and the effect of wheel running on its expression and mechanism of other neurotrophins and different types of exercise (swimming, resistance exercises, etc.). Although we are aware of the information collected so far and s the present challenges in this field, especially the role that neurotrophins and exercising play in treating some common neurological diseases, especially $\mathrm{AD}$, the ground is prepared for further studies and treatment of many diseases. The current study aims to assess the effect of 8 weeks of resistance exercises on the expression of the BDNF gene and other neurotrophins and Trk receptors in an Alzheimer model of male Wistar rats.

\section{Methods}

Experiments were performed on male Wistar rats weighing 230-280 g prepared from the animal reproduction center of Ahvaz Jundishapur University of Medical Sciences, Ahvaz City, Iran. The rats were kept in a room with $22 \pm 2^{\circ} \mathrm{C}$ temperature under 12 hours dark/12 hours light cycle with access to food and water ad libitum. The rats were divided into sham and STZ (Streptozotocin) groups, which received normal saline and streptozotocin via Intracerebroventricular (ICV) injection in cerebral ventricles, respectively. Afterward, the rats were divided into four groups: 1) resting sham, 2) exercising sham, 3) resting Alzheimer, and 4) exercising Alzheimer.

\subsection{Creating the Alzheimer model}

After a few days of taking care of the rats and handling them to ensure their health, the rats were weighed. Then, they were put under anesthesia using ketamine (10\% with the dose of $100 \mathrm{mg} / \mathrm{kg}$ of body weight) and xylazine ( $2 \%$ with the dose of $10 \mathrm{mg} / \mathrm{kg}$ of body weight). In the next step, the rats' skulls were shaved, and the surgery sites were disinfected using betadine solution. The rats were placed on the stereotaxic device, and the exact location was calculated for each rat based on weight and anteroposterior distance between bregma and lambda points. After determining the exact coordinates, the plotted points were marked on the surface of the skulls by ink using the device's axes, and then the skulls were perforated by a manual drill machine. A Hamilton syringe was inserted inside the skull to a definite depth, and then STZ (New Life Science, USA) at a dose of 3 $\mathrm{mg} / \mathrm{kg}$ of body weight, which was freshly prepared in a $5-\mu \mathrm{L}$ serum, was injected intracerebroventricularly at the rate of $1 \mu \mathrm{L} / \mathrm{min}$, and the syringe was kept in its place for 5 more minutes after the injection (Sodhi \& Singh, 2013). Finally, after suturing the wound, the rats were transferred to individual cages until they were recovered from anesthesia. They were under complete care, and then they were placed beside other animals. All following steps were performed for the rats in the sham group as well; however, they were injected with a physiologic serum instead of STZ.

\subsection{Evaluation of passive avoidance memory}

Two weeks after STZ injection, a passive avoidance learning test was performed to evaluate learning and memory and to confirm the induction of the Alzheimer model.

\subsubsection{Shuttle box device and its training steps}

This device is a rectangular box consisting of two similar parts with dimensions of $30 \times 20 \times 20 \mathrm{~cm}$, which is made of Plexiglas. There are parallel metal rods at the bottom of each box with a diameter of $5.2 \mathrm{~mm}$ that are $8 \mathrm{~mm}$ apart. If an electric shock is required in training, it will be applied via these metal rods. A $5.6 \times 8 \mathrm{~cm}$ small 
window connects the two boxes, which can be opened or closed as needed. This device has a controlling part that applies electric shocks to animals' paws by adjusting the intensity, duration, and frequency of the shock (Miu, Andreesucu, Vasiu, \& Olteanu, 2003). Training with the Shuttle box device includes three steps.

\subsubsection{Adaptation}

In this step, each rat becomes familiar with the device for three minutes on the first day of training. They were allowed to freely move between the boxes, from the light part to the dark part.

\subsubsection{Training or acquiring step}

Twenty-four hours after adaptation on the first day, the rats were placed in the light part of the device with the connecting window closed. The hands and feet of the rats were made wet before they were placed in the device so that electric shock can be easily applied. After 30 seconds, the connecting window was opened, and the time it took the rat to enter the dark box was reordered. If the rat did not enter the dark box after 300 seconds, it would be excluded due to lack of cooperation. When the rat entered the dark box, the connecting window was closed, and 5 seconds later, the animal experienced a 1.5 $\mathrm{mA}$ electric shock for 3 seconds (Miu et al., 2003). The rats were taken out of the device after 30 seconds, and other rats were trained in the same manner. The time required for a rat to enter the dark box from the light box was considered the latency time at the beginning of training (before applying the shock), which was used to check the rats' motor and visual abilities (Crawly, 1999).

\subsubsection{Recalling step}

Twenty-four hours after the training step, the recalling of the rats must be evaluated. The trained rats were put in the light box for 30 seconds. Then, the connecting window was opened, and the time for a rat to enter the dark box was recorded. The time allowed to enter the box was 300 seconds, and beyond that time, the rat was excluded from the experiment. When the rat entered the dark box, the time that the rat spent in the dark box was recorded, which was considered as the time spent in the dark box 48 hours after training and applying the shock.

\subsection{Resistance exercises}

Rats in exercising groups exercised three days a week for 8 weeks. A weight was attached to their tails. The rats had to lift this weight and climb a 26-step ladder.
The rats lifted the weight 13 times with their left hands and feet and 13 times with their right hands and feet. The exercising groups spent five days for introduction and orientation. The rats were precisely weighed every week. The initial weight was $30 \%$ of a rat's body weight, which was gradually increased up to $150 \%$ of the rat's body weight in the following 7 weeks $(30 \%$ each week in the first four weeks and $10 \%$ each week in the last three weeks). The weight did not change in the last week. Resting groups were handled every day to minimize the effects of stress (Godfrey et al., 2009). The memory and learning status of the subjects was investigated 24 hours after the last training session by a shuttle box test. Twenty-four hours after the shuttle box test (to avoid the effects of the last exercise session) (Kennedy, Hardman, Macpherson, Scholey \& Pipingas, 2017), the rats were put under deep anesthesia and then were sacrificed by head separation. Then their hippocampus was extracted to study the expression of the genes and stored at $-80^{\circ} \mathrm{C}$. To investigate gene expressions, we used the quantitative RT-PCR method.

\subsection{Total RNA extraction and reverse transcription}

Total RNA was extracted with Tripure RNA Isolation Reagent according to the manufacturer's instructions (Roche, Germany) and quantified by spectrophotometry. Total RNA was reverse transcribed into first strand complementary DNA (cDNA) with RevertAid ${ }^{\mathrm{TM}}$ First Strand cDNA Synthesis Kit (Fermentas, EU).

\subsection{Real-time PCR analysis}

Real-time PCR was performed with an iQ5 Multicolor Real-Time PCR Detection System. PCR reactions were performed under the following conditions: an initial denaturation at $95^{\circ} \mathrm{C}$ for $10 \mathrm{~min}$ and then 45 cycles of denaturation at $95^{\circ} \mathrm{C}$ for $40 \mathrm{~s}$, annealing at $58^{\circ} \mathrm{C}$ for $45 \mathrm{~s}$, extension at $72^{\circ} \mathrm{C}$ for $40 \mathrm{~s}$, and a final extension at $72^{\circ} \mathrm{C}$ for $10 \mathrm{~min}$. All PCR reactions were run in duplicate. The relative expression level (fold changes) of BDNF and other genes in the hippocampus was calculated by the 2-DDCT method. Delta CT is the difference in threshold cycle (CT) values corresponding to GAPDH genes, and DDCt is (DCt resveratrol treated) - (DCt vehicle treated). The quality and correct size of the PCR products were checked by electrophoresis on $2 \%$ agarose gels.

\subsection{Statistical analysis}

Tukey and LSD ANOVA tests were used to determine the significant difference levels between the groups. The 


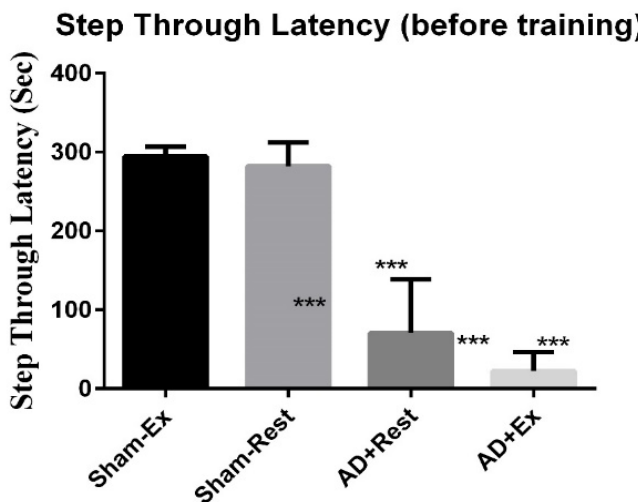

NEUR SCIENCE

Figure 1. Comparison of latency time in entering dark box (shuttle box) before training

***Significant difference with sham group.

Independent $t$ test was used to compare two groups, and $\mathrm{P}<0.05$ was considered significant.

\section{Results}

\subsection{Results of shuttle box test}

As shown in Figure 1, the latency times before resistance exercises were significantly lower in the Alzheimer group compared to the sham group, which indicates that the Alzheimer group effectively lost their memory.

As shown in Figure 2, the latency time to enter the dark box was significantly lower in the resting Alzheimer group than the exercising Alzheimer group. Moreover, the difference was significant between the resting Alzheimer group and the resting and exercising sham groups. It can be concluded that resistance exercises delay entering into the dark box in the exercising Alzheimer groups compared to the resting Alzheimer group and that the memory of the exercising Alzheimer group was improved.

\subsection{Descriptive data}

As Figures 3, 4, 5, $6 \& 7$ show, the mean values of all study variants (BDNF, TrkA, TrkB, and Neurotrophin3

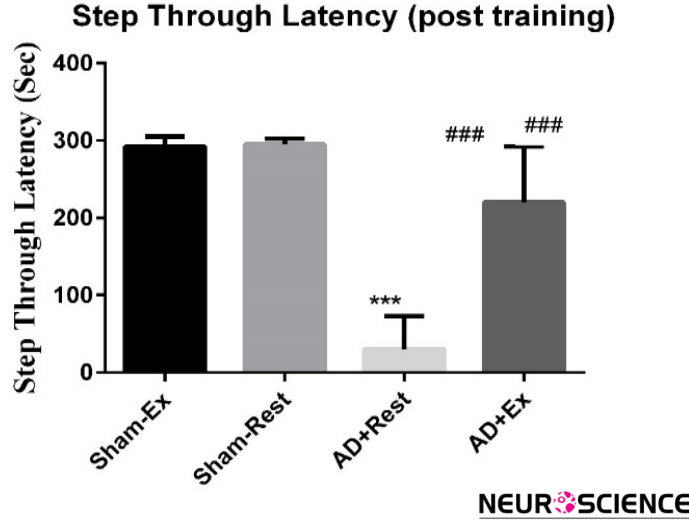

Figure 2. Comparison of latency time in entering dark box (shuttle box) after training

*** Significant difference with sham group; ${ }^{* \# \# S i g n i f i c a n t ~ d i f-~}$ ference with resting Alzheimer group.

[NT3]) except Nerve Growth Factor (NGF) were lower in the Alzheimer group than the Sham group.

Also, the mean values of all study variants (BDNF, NGF, TrkA, TrkB, and NT3) were higher in the exercising group than in the resting group.

Results of the test for comparison of BDNF variant between two rat groups shows that with an error level of less than $5 \%$ and confidence interval of over $95 \%$, there is a significant difference between the resting and exercising Alzheimer rat groups regarding BDNF levels. Therefore, in this situation $(\mathrm{t}=-10.938, \mathrm{P}<0.0001)$ and considering that the mean BDNF level is higher in exercising rats $(0.9215155)$ compared to resting rats (0.4741931), the mean BDNF level is higher in the exercising rats in comparison with the resting rats. It can be stated that 8 weeks of resistance exercise significantly affect the expression of the BDNF gene in the Alzheimer model male Wistar rats (Table 1).

The test results for comparison of NGF variant between two rat groups showed that with a type I error level of less than $5 \%$ and confidence interval of over $95 \%$, there is a significant difference between the resting and

Table 1. Results of independent $t$ test for comparison of BDNF variant in Alzheimer rats group

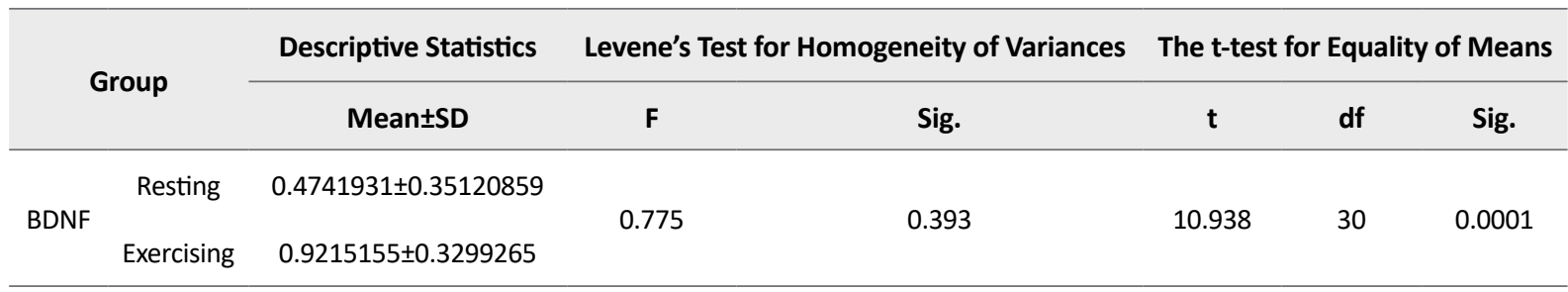



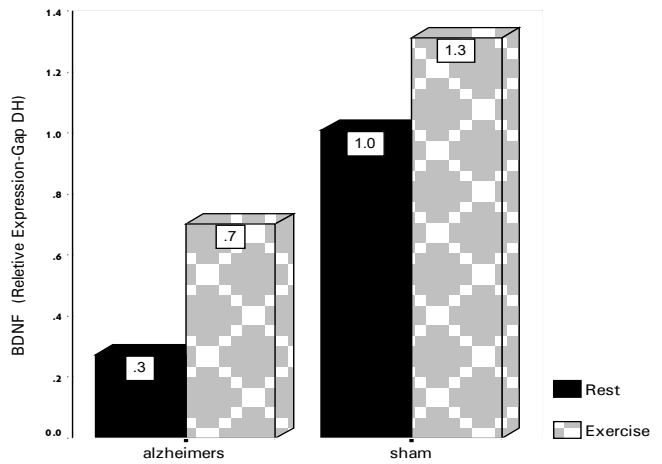

NEUR SCIENCE

Figure 3. Distribution of scores and mean of BDNF in the resting and exercising groups in the Alzheimer and Sham rat groups

exercising Alzheimer rat groups regarding NGF levels. In this situation $(\mathrm{t}=-8.254, \mathrm{P}<0.0001)$ and considering that the mean NGF level is higher in the exercising rats (1.3630569) compared to the resting rats (0.9144923), 8 weeks of resistance exercise then significantly affect the expression of the NGF gene in the Alzheimer model male Wistar rats (Table 2).

The test results for comparison of the TrkA variant between two rat groups showed that with an error level of less than $5 \%$ and confidence interval of over $95 \%$, there is a significant difference between the resting and exercising Alzheimer rat groups regarding TrkA levels. In this situation ( $\mathrm{t}=-9.870, \mathrm{P}<0.0001)$, considering that the mean TrkA level is higher in the exercising rats (0.7400961) compared to resting rats (0.4010958), so 8 weeks of resistance exercise significantly affect the expression of the TrkA gene in the Alzheimer model male Wistar rats (Table 3 ).

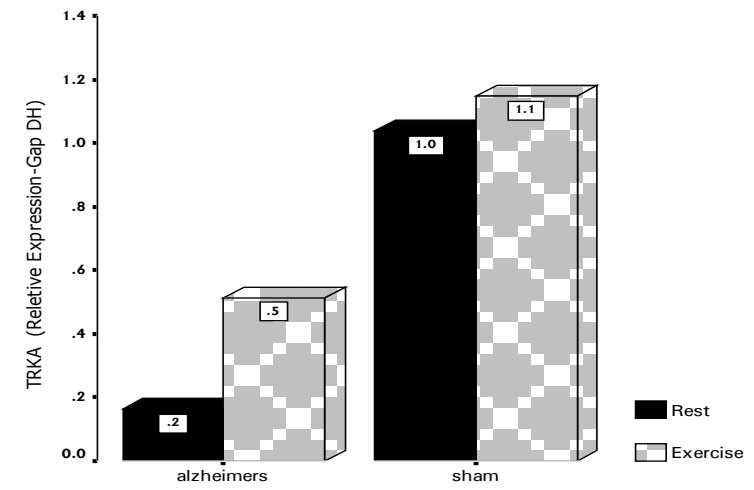

NEUR SCIENCE

Figure 5. Distribution of scores and mean of TrkA in the resting and exercising groups in the Alzheimer and sham rat groups

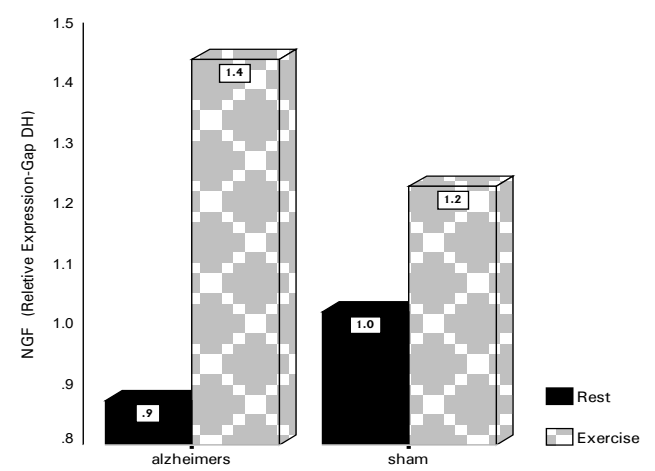

NEUR SCIENCE

Figure 4. Distribution of scores and mean of NGF in the resting and exercising groups in the Alzheimer and Sham rat groups

The test results for comparison of TrkB variant between two rat groups showed that with an error level of less than $5 \%$ and confidence interval of over $95 \%$, there is a significant difference between the resting and exercising Alzheimer rat groups regarding TrkB levels. In this situation $(\mathrm{t}=-7.026, \mathrm{P}<0.0001)$, considering that the mean TrkB level is higher in exercising rats $(0.9957332)$ compared to resting rats (0.2993140), so 8 weeks of resistance exercise significantly affect the expression of the TrkB gene in the Alzheimer model male Wistar rats (Table 4).

The test results for comparison of NT3 variant between two rat groups showed that with an error level of less than $5 \%$ and confidence of over $95 \%$, there is a significant difference in NT3 levels between the resting and exercising Alzheimer rat groups. In this situation ( $\mathrm{t}=-$ 8.122, $\mathrm{P}<0.0001$ ), considering that the mean NT3 level is higher in exercising rats $(0.97871482)$ compared to resting rats $(0.57636236)$ so, 8 weeks of resistance exercise significantly affect the expression of the NT3 gene in the Alzheimer model male Wistar rats (Table 5).

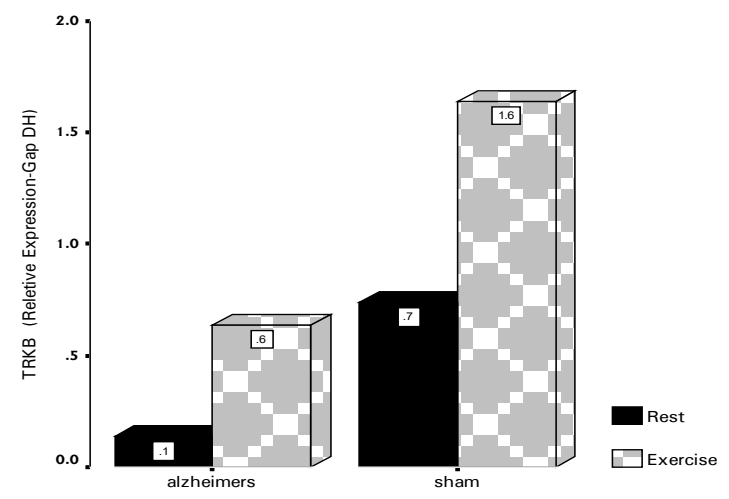

NEUR:SCIENCE

Figure 6. Distribution of scores and mean of TrkB in resting and exercising groups in the Alzheimer and sham rat groups 


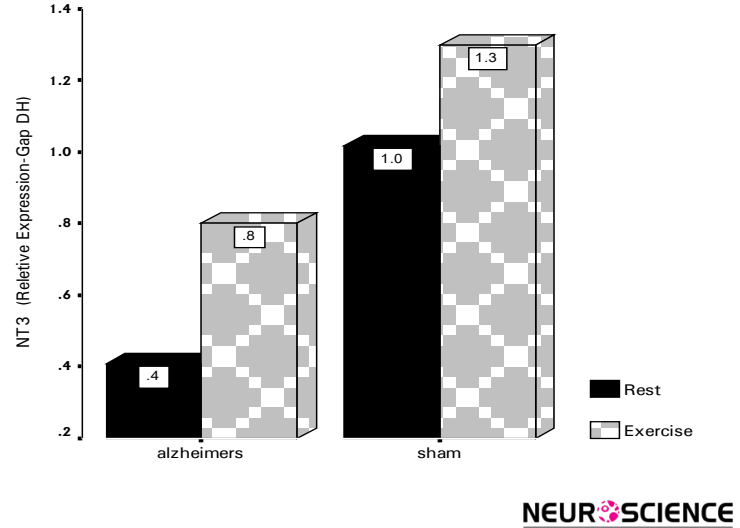

Figure 7. Distribution of scores and mean of NT3 in resting and exercising groups in the Alzheimer and sham rat groups

\section{Discussion}

This study showed that the learning and memory of the rats that received STZ via ICV injection were significantly lower than those in the sham group. Moreover, resistance exercisers improved learning in Alzheimer rats. In addition, resistance exercises increased the expression of the BDNF gene, other neurotrophins, and Trk receptors.

Several studies have been conducted on the advantages of physical activity and exercise on brain functions such as improving learning and memory (Diederich et al., 2017), cognitive function (Maejima, Kanemura, Kokubun, Murata \& Takayanagi, 2018), neurogenesis (Jiang et al., 2018), and recovery from brain damages (Kim et al., 2013), and they have all demonstrated these beneficial effects. Regular exercise can positively influence cognitive ability, reduce the rate of cognitive aging, and even reduce the risk of $\mathrm{AD}$ and other dementias (Kennedy et al., 2017). Studies have proved that a decrease in the BDNF gene's expression causes some problems in synaptic functions and leads to loss of memory and Alzheimer (Vafaei, Jezek, Bures, Fenton \& Rashidy-Pour, 2007). On the other hand, cholinergic activity is increased by physical exercises, and regulation of the cholinergic system plays a role in neuronal plasticity (Cotman \& Berchtold, 2002). Moreover, it is stated that physical activity can probably improve behavioral disorders by reducing the level of A- $\beta_{1-42}$ through the production of higher amounts of neurotrophic agents (IGF-1, BDNF, and NGF), which are essential for neuronal survival and synaptic plasticity (Terzioglu \& Larsson, 2007). Lou et al. indicated that exercising increases neurogenesis in rats and the production of mRNA of $B D N F$ gene in neuronal plasticity, thus improving brain function, learning, and memory (Lou, Liu, Chang \& Chen, 2008).

Most of the conducted studies have assessed the effects of exercising on the BDNF gene expression while other neurotrophins have not been studied, and most of these studies have also been performed on healthy and nonAlzheimer animals. Thus resources to compare the current study's results with other similar studies are limited. This study showed that resistance exercises significantly increased BDNF, NGF, NT3, TrkA, and TrkB in exercising rats compared to resting rats in the hippocampi of the Alzheimer rats group. These results are consistent with Radak et al. study in 2010 (Radak et al., 2010), LangeAsschenfeldt et al. study in 2008 (Lange-Asschenfeldt \& Kojda, 2008), and Vaynman et al. study in 2004 (Vaynman et al., 2004). They reported that moderate to severe physical exercise in animal models increased the production of antioxidant enzymes (especially superoxide dismutase), eNOS, BDNF, neuron growth factor, insulin-like growth factor, and vascular endothelial growth factor. Moreover, physical exercise reduces the release of reactive oxygen species and A- $\beta$ plaque density, especially in neural parts responsible for cognitive functions (specifically memory) such as the hippocampus.

These results support the idea that resistance exercises are helpful for BDNF-signaling-dependent hippocampus plasticity since BDNF binding to TrkB specific receptor is the main signaling pathway in synaptic plasticity in the hippocampus. Three main signaling pathways are activated by binding BDNF to TrkB: MAP kinase pathway, Phosphatidylinositol 3-Kinase (PI3K), and Phospholipase C, Gamma (PLCG). These three pathways are activated after binding a ligand with the receptor that finally results in neuron proliferation, differentiation, and survival. Among all these, the third pathway, in which PKC

Table 2. Results of Interferential Test for comparison of NGF variant in the Alzheimer rats group

\begin{tabular}{|c|c|c|c|c|c|c|c|}
\hline \multirow{2}{*}{\multicolumn{2}{|c|}{ Group }} & \multirow{2}{*}{$\begin{array}{c}\text { Descriptive Statistics } \\
\text { Mean } \pm S D\end{array}$} & \multicolumn{2}{|c|}{ Levene's Test for Homogeneity of Variances } & \multicolumn{3}{|c|}{ The t-test for Equality of Means } \\
\hline & & & $\mathbf{F}$ & Sig. & $\mathbf{t}$ & df & Sig. \\
\hline NGF & $\begin{array}{l}\text { Resting } \\
\text { Exercising }\end{array}$ & $\begin{array}{c}0.9144923 \pm 0.10122112 \\
1.3630569 \pm 0.19354183\end{array}$ & 8.821 & 0.010 & -8.254 & 30 & 0.0001 \\
\hline
\end{tabular}


Table 3. Results of independent $t$ test for comparison of TrkA variant in the Alzheimer rats group

\begin{tabular}{|c|c|c|c|c|c|c|c|}
\hline \multirow{2}{*}{\multicolumn{2}{|c|}{ Group }} & \multirow{2}{*}{$\begin{array}{c}\text { Descriptive Statistics } \\
\text { Mean } \pm \text { SD }\end{array}$} & \multicolumn{2}{|c|}{ Levene's Test for Homogeneity of Variances } & \multicolumn{3}{|c|}{ The t-test for Equality of Means } \\
\hline & & & $\mathbf{F}$ & Sig. & $\mathbf{t}$ & df & Sig. \\
\hline \multirow{3}{*}{ TrkA } & Resting & $0.4010958 \pm 0.41187538$ & \multirow{3}{*}{9.865} & \multirow{3}{*}{0.07} & \multirow{3}{*}{-9.870} & \multirow{3}{*}{30} & \multirow{3}{*}{0.0001} \\
\hline & & & & & & & \\
\hline & Exercising & $0.7400961 \pm 0.32711303$ & & & & & \\
\hline
\end{tabular}

NEUR SCIENCE

Table 4. Results of the Iindependent $t$-test for comparison of TrkB variant in the Alzheimer rats group

\begin{tabular}{|c|c|c|c|c|c|c|c|}
\hline \multirow{2}{*}{\multicolumn{2}{|c|}{ Group }} & \multirow{2}{*}{$\begin{array}{c}\text { Descriptive Statistics } \\
\text { Mean } \pm \text { SD }\end{array}$} & \multicolumn{2}{|c|}{ Levene's Test for Homogeneity of Variances } & \multicolumn{3}{|c|}{ The t-test for Equality of Means } \\
\hline & & & $\mathbf{F}$ & Sig. & $\mathbf{T}$ & df & Sig. \\
\hline \multirow[b]{2}{*}{ TrkB } & Resting & $0.2993140 \pm 0.38059510$ & & & & & \\
\hline & Exercising & $0.9957332 \pm 0.52784721$ & 6.804 & 0.02 & -7.026 & 30 & 0.0001 \\
\hline
\end{tabular}

and calcium are engaged, is more important due to the crucial role of exercising in calcium homeostasis. Activation of PLCG leads to IP3 and DAG-related signaling. IP3 causes calcium release from intracellular storages, and DAG activates PKC, which leads to hypersensitivity of contractile apparatus, calcium release, and the subsequent proliferation and migration of myocytes. However, the more important pathway in neurons is the IP3 pathway which results in proliferation, differentiation, and survival of neurons, especially in the hippocampus, which leads to improvement of long-term memory and increased synaptic transfers as well (Bariohay, Lebrun, Moyse \& Jean, 2005; Gottschalk et al., 1999).

Previous studies have proved that aerobic exercises can increase BDNF and TrkB levels (Hosseini, Mojtahedi, Kordi, Shabkhiz \& Fallah Omran, 2012; Liu et al., 2009; Lou et al, 2008). Several human studies have assessed the relationship between resistance exercises and plasticity-related molecules in the peripheral bloodstream (Cassilhas et al., 2007; Schiffer, Schulte, Hollmann, Bloch \& Strüder, 2009); although, few studies have assessed BDNF in hippocampus tissue which is its main synthesis part. Among these limited number of studies, Suijo et al.
(2013) have evaluated the effects of 14 days of voluntary aerobic running exercises and resistance exercises on plasticity-related factors, BDNF, and CREB in the hippocampus of rats. These authors have also shown the improvement of learning and memory functions using the water maze test. Results of their study have shown that 14 days of running and resistance exercises caused a significant increase in the amount of proteins and genes of these factors compared with the control group. This increase was more prominent in the aerobic exercises group compared to the resistance exercises group.

Interestingly, researchers found a positive correlation between BDNF level in the hippocampus and amount of work in aerobic running, while no correlation was observed between BDNF level and amount of resistance exercises. This finding suggests that the increase in BDNF levels in the hippocampus results from different mechanisms. In other words, BDNF activation following resistance exercises is probably not dependent on energy cost (Suijo et al., 2013). Lee et al. (2012) have also assessed both exercise models of the aforementioned study and investigated BDNF, CREB, and TrkB levels

Table 5. Results of the independent t-test for comparison of NT3 variant in the Alzheimer rats group

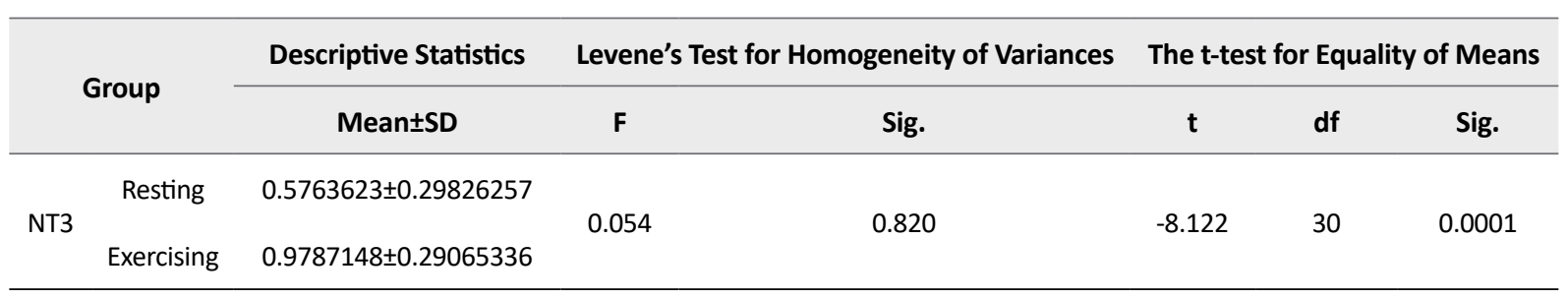


in the hippocampus of male Wistar rats. Both of these training methods improved cognitive functions.

Contrary to Suijo et al. study (2013), the results of their study showed that the levels of these three factors were increased more by resistance exercises than aerobic exercises. They stated that higher levels of these factors are caused by lower corticosterone levels in the plasma of the animals in the resistance exercises group compared to the aerobic exercises group (23.1 against $38.5 \mathrm{ng} / \mathrm{L}$ ) since it has been proven that cortisol can inhibit BDNF expression (Lee et al., 2012). Consistent with the results of the current and Lee et al. studies, Ravasi et al. assessed the effects of 8 weeks of forced resistance and strength exercises on the amount of changes of BDNF and cortisol in the plasma levels of rats. They showed that at the end of the fourth and sixth weeks, BDNF levels increased more in the resistance exercises group than in the endurance exercises group. Moreover, cortisol levels were lower in the resistance exercises group (Ravasi, Pournemati, Kordi \& Hedayati, 2013). Although plasma levels of BDNF were measured in this study, and tissues other than the brain, such as skeletal muscles, can release BDNF into plasma, the increase in BDNF levels following resistance exercises cannot merely be attributed to the brain and hippocampus. Therefore because of the nature of resistance exercises that heavily affect skeletal muscle tissues, this increase in BDNF levels may be merely caused by BDNF release from skeletal muscles.

As a result of exercising, brain blood flow, the number of brain cells in the hippocampus, and secretion of protective molecules such as BDNF are increased (Huang, Larsen, Ried-Larsen, Møller \& Andersen, 2014). These processes as a whole can enhance memory and postpone AD progress (Coelho et al., 2014). Additionally, since exercising increases VEGF release, new capillaries may form in different parts of the brain leading to better blood supply (Wang et al., 2015).

Nutritional neural factors such as BDNF and IGF-1 can play a significant role in regulating neural tissue formation and reduction of amyloid deposition (Lewitt \& Boyd, 2019). Considering the relationship between neural nutritional factors and the formation of neural tissue and the evidence on the effects of strength exercises on the levels of BDNF and IGF-1 (Cassilhas et al., 2007; Coelho et al., 2014), strength exercises may reduce the effects of aging and the AD by increasing neural tissue formation.

\section{Conclusion}

This study indicates that 8 weeks of resistance exercises increased the expression of BDNF, NT3, and NGF genes and TrkA and TrkB receptors in the Alzheimer model Wistar rats. Therefore, resistance exercises can be used as a proper model to help patients with AD. However, this issue requires further research on other clinical aspects of these patients.

\section{Ethical Considerations}

\section{Compliance with ethical guidelines}

The animal experiments were carried out according to the Ethics Committee of IUMS to care and use laboratory animals (following the National Institutes of Health Guide for Care and Use of Laboratory Animals: NIH Publication 1996). The efforts were made to minimize unnecessary pain and suffering within labs.

\section{Funding}

This research did not receive any grant from funding agencies in the public, commercial, or non-profit sectors.

\section{Authors' contributions}

All authors equally contributed to preparing this article.

\section{Conflict of interest}

The authors declared no conflict of interests.

\section{Acknowledgments}

We appreciate the Physiology Department of Ahvaz Jundishapur University of Medical Sciences and the Faculty of Physical Education, Shahid Chamran University of Ahvaz.

\section{References}

Bariohay, B., Lebrun, B., Moyse, E., \& Jean, A. (2005). Brain-derived neurotrophic factor plays a role as an anorexigenic factor in the dorsal vagal complex. Endocrinology, 146(12), 561220. [DOI:10.1210/en.2005-0419] [PMID]

Cassilhas, R. C., Vianna, V. R., Grassmann, V., Santos, R. T., Santos, R. F., \& Tufik, S., er al. (2007). The impact of resistance exercise on the cognitive function of the elderly. Medicine $\mathcal{E}$ Science in Sports \& Exercis, 39(8), 1401-7. [DOI:10.1249/ mss.0b013e318060111f] [PMID] 
Coelho, F. G. M., Vital, T. M., Stein, A. M., Arantes, F. J., Rueda A. V., \& Camarini, R., et al. (2014). Acute aerobic exercise increases brain-derived neurotrophic factor levels in elderly with Alzheime's disease. Journal of Alzheimer's Disease, 39(2), 401-8. [DOI:10.3233/JAD-131073] [PMID]

Cotman, C. W., \& Berchtold, N. C. (2002). Exercise: A behavioral intervention to enhance brain health and plasticity. Trends in Neurosciences, 25(6), 295-301. [DOI:10.1016/S0166-2236(02)02143-4]

Crawly, J. N. (1999). Behavioral phenotyping of transgenic and knockout mice: Experimental design and evaluation of general health, sensory functions, motor abilities, and specific behavioral tests. Brain Research, 835(1), 18-26. [DOI:10.1016/S00068993(98)01258-X]

de Eulate, R. G., Goñi, I., Galiano, A., Vidorreta, M., Recio, M., \& Riverol, M., et al. (2017). Reduced cerebral blood flow in mild cognitive impairment assessed using phase-contrast MRI. Journal of Alzheimer's Disease, 58(2), 585-95. [DOI:10.3233/JAD161222] [PMID]

Diederich, K., Bastl, A., Wersching, H., Teuber, A., Strecker, J. K., Schmidt, A., et al. (2017). Effects of different exercise strategies and intensities on memory performance and neurogenesis Frontiers in Behavioral Neuroscience, 11, 47. [DOI:10.3389/fnbeh.2017.00047] [PMID] [PMCID]

Furcila, D., DeFelipe, J., \& Alonso-Nanclares, L. (2018). A study of amyloid- $\beta$ and phosphotau in plaques and neurons in the hippocampus of Alzheimer's disease patients. Journal of Alzheimer's Disease, 64(2), 417-35. [DOI:10.3233/JAD-180173] [PMID] [PMCID]

Godfrey, J. K., Kayser, B. D., Gomez, G. V., Bennet, J., \& Jaque, S. V., \& Sumida, K. D. (2009). Interrupted resistance training and BMD in growing rats. International Journal of Sports Medicine, 30(8), 579-84. [DOI:10.1055/s-0029-1202823] [PMID]

Gottschalk, W. A., Jiang, H., Tartaglia, N., Feng, L., Figurov, A., \& $\mathrm{Lu}, \mathrm{B}$. (1999). Signaling mechanisms mediating BDNF modulation of synaptic plasticity in the hippocampus. Learning $\mathcal{E}$ Memory, 6(3), 243-56. [PMID] [PMCID]

Hosseini, S. E., Mojtahedi, Sh., Kordi, M. R., Shabkhiz, F., \& Fallah Omran, S. (2012). [Effect of short term and light forced treadmill running on BDNF and TrkB in the hippocampus of adult wistar male rats (Persian)]. Razi Journal of Medical Sciences, 19(101), 617. http://rjms.iums.ac.ir/article-1-2264-en.html

Huang, T., Larsen, K., T., Ried-Larsen, M., Møller, N., C., \& Andersen, L., B. (2014). The effect of physical activity and exersice on brain-derived neurotrophic factor in healthy humans: A review. Scandinavian Journal of Medicine \& Science in Sports, 24(1), 1-10. [DOI:10.1111/sms.12069] [PMID]

Jellinger, K. A. (2009). Recent advances in our understanding of neurodegeneration. Journal of Neural Transmission, 116(9), 111162. [DOI:10.1007/s00702-009-0240-y] [PMID]

Jiang, L., Ma, J., Zhang, Y., Zhou, C. N., Zhang, L., \& Chao, F. L., et al. (2018). Effect of running exercise on the number of the neurons in the hippocampus of young transgenic APP/PS1 mice. Brain Research, 1692, 56-65. [DOI:10.1016/j.brainres.2018.04.033] [PMID]

Kennedy, G., Hardman, R. J., Macpherson, H., Scholey, A. B., \& Pipingas, A. (2017). How does exercise reduce the rate of ageassociated cognitive decline? A review of potential mechanisms. Journal of Alzheimer's Disease, 55(1), 1-18. [DOI:10.3233/ JAD-160665] [PMID]
Kim, S. E., Ko, I. G., Shin, M. S., Kim, C. J., Jin, B. K., \& Hong H. P., et al. (2013). Treadmill exercise and wheel exercise enhance expressions of neutrophic factors in the hippocampus of lipopolysaccharide-injected rats. Neuroscience Letters, 538, 54-9. [DOI:10.1016/j.neulet.2013.01.039] [PMID]

Lange-Asschenfeldt, Ch., \& Kojda, G. (2008). Alzheimer's disease, cerebrovascular dysfunction and the benefits of exercise: From vessels to neurons. Experimental Gerontology, 43(6), 499504. [DOI:10.1016/j.exger.2008.04.002] [PMID]

Lee, M. Ch., Okamoto, M., Liu, Y. F., Inoue, K., Matsui, T., \& Nogami, H., et al. (2012). Voluntary resistance running with short distance enhances spatial memory related to hippocampal BDNF signaling. Journal of Applied Physiology, 113(8), 12606. [DOI:10.1152/japplphysiol.00869.2012] [PMID]

Lewitt, M. S., \& Boyd, G. W. (2019). The role of insulin-like growth factors and insulin-like growth factor-binding proteins in the nervous system. Biochemistry Insights, 12. [DOI:10.1177/1178626419842176] [PMID] [PMCID]

Liu, Y., F., Chen, H. I., Wu, Ch. L., Kuo, Y. M., Yu, L., \& Huang A. M., et al. (2009). Differential effects of treadmill running and wheel running on spatial or aversive learning and memory: Roles of amygdalar brain-derived neurotrophic factor and synaptotagmin I. The Journal of Physiology, 578(13), 3221-31. [DOI:10.1113/jphysiol.2009.173088] [PMID] [PMCID]

Lou, S. J., Liu, J. Y., Chang, H., \& Chen, P. J. (2008). Hippacampal neurogenesis and gene expression depend on exercise intensity in juvenile rats. Brain Research, 1210, 48-55. [DOI:10.1016/j. brainres.2008.02.080] [PMID]

Maejima, H., Kanemura, N., Kokubun, T., Murata, K., \& Takayanagi, K. (2018). Exercise enhances cognitive function and neurotrophin expression in the hippocampus accompanied by changes in epigenetic programming in senescence-accelerated mice. Neuroscience Letters, 665, 67-73. [DOI:10.1016/j. neulet.2017.11.023] [PMID]

Mayeux, R. (2003). Epidemiology of neurodegeneration. Annual Review of Neuroscience, 26, 81-104. [DOI:10.1146/annurev. neuro.26.043002.094919] [PMID]

Meamar, R., Dehghani, L., Ghasemi, M., Saadatnia, M., Basiri, K., \& Alaei Faradonbeh, N., et al. (2013). Enalapril protects endothelial cells against induced apoptosis in Alzheimers disease. Journal of Research in Medical Sciences, 18(Suppl 1), S1-5. [PMID] [PMCID]

Miu, A. C., Andreesucu, C. E., Vasiu, R., \& Olteanu, A. I. (2003) A behavioral and histological study of the effects of long-term exposure of adult rats to aluminum. International Journal of $\mathrm{Neu}$ roscience, 113(9), 1197-211. [DOI:10.1080/00207450390232292] [PMID]

Mohaddes Aredebili, S. M., Yeghaneh, T., Gharesouran, J., Rezazadeh, M., Farhoudi, M., \& Ayromlou, H., et al. (2011) [Genetic association of TNF- $\alpha-308 \mathrm{G} / \mathrm{A} \&-863 \mathrm{C} / \mathrm{A}$ polymorphisms with late onset Alzheimers disease in Azeri Turk population of Iran (Persian)]. Journal of Research in Medical Sciences, 16(8), 1006-13. http://jrms.mui.ac.ir/index.php/jrms/ article/view/6877

Mohammadzadeh, E., Alipour, F., \& Khallaghi, B. (2014). [Evaluation of spatial memory impairment after intracerebroventricular streptozocin injection in adult rats (Persian)]. Shefaye Khatam, 2(1), 40-5. [DOI:10.18869/acadpub.shefa.2.1.40] 
Özbeyli, D., \& Kasımay Çakır, Ö. (2017). The effects of different exercise modalities in Alzheimer's disease. Clinical and Experimental Health Sciences, 7(1), 27-31. https://dergipark.org.tr/ en/pub/clinexphealthsci/issue/35008/388414

Radak, Z., Hart, N., Sarga, L., Koltai, E., Atalay, M., \& Ohno , $\mathrm{H}$., et al. (2010). Exercise plays a preventive role against Alzheimer's disease. Journal of Alzheimer's Disease, 20(3), 777-83. [DOI:10.3233/JAD-2010-091531] [PMID]

Ravasi, A. A., Pournemati, P., Kordi, M. R., \& Hedayati, M. (2013). [The effects of resistance and endurance training on BDNF and cortisol levels in young male rats (Persian)]. Journal of Sport Biosciences, 1(16), 49-78. [DOI:10.22059/ JSB.2013.30458]

Schiffer, T., Schulte, S., Hollmann, W., Bloch, W., \& Strüder, H. K. (2009). Effects of strength and endurance training on brainderived neurotrophic factor and insulin-like growth factor 1 in humans. Hormone and Metabolic Research, 41(3), 250-4. [DOI:10.1055/s-0028-1093322] [PMID]

Sodhi, R. K., \& Singh, N. (2013). All-trans retinoic acid rescues memory deficits and neuropathological changes in mouse model of streptozotocin-induced dementia of Alzheimer's type. Progress in Neuro-Psychopharmacoligy \& Biological Psychiarity, 40, 38-46. [DOI:10.1016/j.pnpbp.2012.09.012] [PMID]

Suijo, K., Inoue, S., Ohya, Y., Odagiri, Y., Takamiya, T., \& Ishibashi, H., et al. (2013). Resistance exercise enhances cognitive function in mouse. International Journal of Sports Medicine, 34(4), 368-75. [DOI:10.1055/s-0032-1323747] [PMID]

Terzioglu, M., \& Larsson, N. G. (2007). Mitochondrial dysfunction in mammalian ageing. In D. J. Chadwick, \& J. Goode (Eds.), Mitochondrial biology: New perspectives: Novartis foundation symposium 287 (pp. 197-208). Vol. 287. Chichester: John Wiley \& Sons Ltd. [DOI:10.1002/9780470725207.ch14] [PMID]

Vafaei, A. A., Jezek, K., Bures, J., Fenton, A. A., \& Rashidy-Pour, A. (2007). Post-training reversible inactivation of the rat's basolateral amygdala interfers with hippocampus- dependent place avoidance memory in a time-dependent manner. Neurobiology of Learning and Memory, 88(1), 87-93. [DOI:10.1016/j. nlm.2007.02.004] [PMID]

Vaynman, Sh., Ying, Zh., \& Gomez-Pinilla, F. (2004). Hippocampal BDNF mediates the efficacy of exercise on synaptic plasticity and cognition. European Journal of Neuroscience, 20(10), 2580-90. [DOI:10.1111/j.1460-9568.2004.03720.x] [PMID]

Wang, S., Chen, L., Zhang, L., Huang, Ch., Xiu, Y., \& Wang, F., et al. (2015). Effects of long-term exercise on spatital learning, memory ability, and cortical capillaries in aged rats. Medical Science Monitor, 21, 945-54. [DOI:10.12659/MSM.893935] [PMID] [PMCID]

Yuan, J., \& Yankner, B. A. (2000). Apoptosis in the nervous system. Nature, 407(6805), 802-9. [DOI:10.1038/35037739] [PMID] 
This Page Intentionally Left Blank 